\title{
KRONIK
}

\section{Yoksulluk ve Eşitsizlik Üzerine: Eski Mesele, Yeni Aktörler, Yine Düş Kırıklığı}

\author{
Yard.Doç.Dr. Emel Memiş, A.Ü. Siyasal Bilgiler Fakültesi
}

\begin{abstract}
Thomas Piketty '21. Yüzyılda Sermaye' başlıklı kitabında bugünün zengin ülkelerinde gelir bölüşümü ve servet dağılımına dair iki yüzyıl geriye giden istatistikler sunuyor. Yayınlanır yayınlanmaz en çok satanlar listesine giren kitabında, Piketty'in öne sürdüğü temel argüman yaklaşık yüz elli yıl önce yazılmıştı: eşitsizlik kapitalizme içkindir ve artan eşitsizlik sistemin kaçınılmaz bir gerçeğidir. Bu sav nedense ilk kez bugün Piketty-çılgınlığı olarak adlandırılacak derecede ilgi gördü. O kadar ki, kitaptan oldukça etkilenen Katolik lideri Papa Francis bir tivitinde: '..eşitsizlik tüm kötülüklerin kökenidir..' yazdı. Hatta daha da ileri giderek vaazlarından birinde şöyle dedi '...piyasanın, finansal spekülasyonun mutlak hakimiyetini bertaraf ederek, eşitsizliğin yapısal nedenlerini ortadan kaldırarak yoksulluk meselesine radikal bir çözüm getirilmediği sürece dünyanın sorunlarına ve bu nedenle de herhangi bir soruna çözüm bulunamaz.'

Yine, bu yılın başlarında Amerika'da, Merkez Bankası başkanlık koltuğuna gelen ve ilk kadın başkan ünvanını alan Janet Yellen de benzer yorumlar yaptı: ‘...ekonominin en büyük sorunu eşitsizlikdir...’. Oldukça ilginç zamanlarda yaşıyor olmalıyız. Bir başka kıtada, Avrupa Merkez Bankası yönetim kurulu üyeleri, merkez bankasının eşitsizliği ve yoksulluğu azaltmak için neler yapabileceğini tartışmaya başladı, para politikasının eşitsizlik üzerine etkilerini araştırmaya açtı. Bütün bunlar yeni bir aydınlanmaya $\mathrm{m}$ iş̧aret ediyor? Birdenbire mi aydınlandı bu aktörler? Bundan yirmi yıl öncesine, hatta on y1l da yeterli olur, on y1l geriye gidelim. Amerika'da, Avrupa'da merkez bankaları temsilcilerinin eşitsizliği araştıracağı, bırakın araştırmayı, eşitsizlikten söz edeceği düşünülebilir miydi? Fiyat istikrarı değil miydi para politikası yapıcılarının obsesyonu? Piketty-çılgınlığına, çılgınlık denmesi pek de yersiz
\end{abstract}


sayılmaz. İçinde yüze yakın grafik ve tablo içeren altı-yedi yüz sayfalık bir kitap nasıl çok satanlar listesine çıkabildiği pek anlaşılabilir birşey değil. Ancak bu yoğun ilgi madalyonun sadece bir yüzünü oluşturuyor. Öbür yüzünü ise bir panik, endişeli bir heyecan hali sarmış durumda. Asıl dert, 2007'de yaşadığımız büyük çöküş (Büyük Resesyon) ve sonrasında, 1930'larda Büyük Bunalım sonrası gelirin yeniden dağıtılması sürecinin tekrarlanacağı düşüncesi olabilir mi?

Piketty'nin de ortaya koyduğu bulgulardan biri şunu gösteriyor: iki dünya savaşı arasındaki dönemde istatistiklere göre eşitsizlik azalıyor, hatta bu dönem, eşitsizliğin gerilediği tek dönem olarak tespit ediliyor. Anomali mi, hayır, tam aksine normal, sistemin doğası gereği. 1930'larda gelir dağılımı ücretlerden yana gelişme gösteriyor ve bunun Altın Çağ olarak adlandırılan dönemin ardındaki temel etmenlerden biri olduğu da belirtiliyor. Buna rağmen, öbür yüzdeki panik durdurulamıyor. 2014 Dünya Ekonomik Forumu'nda alınan anket sonuçlarına göre küresel ekonomiye en büyük tehdit artan gelir eşitsizliği olarak tespit edilmiş. Gelişmeler gösteriyor ki konu üzerine tartışmalar önümüzdeki dönemde de devam edecek. $\mathrm{Bu}$ tartışmalar bir anlamda, sermayenin kendini kendinden koruma çabasına ve bu çabanın yarattığı sancılı sürece işaret ediyor aslında. Yoğun ilginin ardındaki panik düşünüldüğ̈̈nde, papa Francis'in tiviti ile merkez bankalarındaki eş zamanlı odak sürçmesi de bizce daha anlaşılır oluyor.

21. Yüzyılda Sermaye, başta iktisatçılar olmak üzere akademi dünyasında da çokça tartışıldı ve eleştirildi. Konu üzerine çalışan birçok akademisyen kitabın değerlendirilmesine katkıda bulundu. Öne çıkan temel eleştirilerin başında, kullandığı sermaye kavramının tanımının altı boş olduğu düşüncesi geldi. Bu sermaye ile Marks'in sermaye kavramı arasında ilişki kurulmasının yanlış olduğu, fiyat etkilerini de barındırdığı için kavramın sorunlu olduğu, ünlü Cambridge-Cambridge tartışmasına konu olan sözkonusu çelişkilerden kurtulamadığ 1 savunuldu. Piketty'in izlediği temel göstergenin (sermaye getiri oranının ekonomik büyüme oranı ile kıyaslanması) yeni keşfedilmediği de eleştiriler arasında çok yer buldu: Marks, Kalecki, Kuznets, Keynes ve Pasinetti'nin çalışmalarına dikkat çekildi (bkz. Patnaik; Galbraith; Taylor; Boratav; Köse; Tonak; Aydınonat). Sosyal bilimin diğer alanlarından bilim üreticileri de, rakamların, Piketty'in de arzu ettiği gibi, iktisatçıların tekeline bırakılmayacak kadar önemli bulduklarından olsa gerek, değişik bakış açılarıyla değerlendirmeler sundu.

$\mathrm{Bu}$ bağlamda siyaset bilimci Ziliah Eisenstein'ın uyarı niteliğindeki değerlendirmesinin ayrıcalıklı bir önemi olduğunu düşünüyorum. Tıpkı kitapta yer alan analizler gibi yapılan değerlendirmelerin de sınırlıllğına dikkat çekiyor çünkü Eisenstein. Sermayenin farklı ayrımcılık ve sömürü süreçlerinin bir bileşkesi (intersectional) olduğunun altını çizerek, kapitalist birikimi, sınıflı, 
1rkçı ve cinsiyetçi toplumsal yapılara dahil ve bu yapıların üzerinde yükselen bir süreç olarak tanımlıyor. Ona göre eşitsizliği anlamak ancak birikimin sömürü süreçlerinin çözümlenmesiyle ve bu süreçlerin de yalnızca 1rkçı, ataerkil güç ilişkilerinin anlaşılmasıyla mümkün olabilir. Eisenstein, Piketty’nin eşitsizliği çözümlemekten çok, yüksek eşitsizliğin nedenini araştırmak olduğunu belirtiyor ve 21. yüzyılda hala sermayenin ve eşitsizliğin tekil, tekbiçimli bir yaratık olarak varsayılmasını yadırgıyor. Sermaye, eğer bir toplumsal ilişkiler bütünü olarak tanımlanıyorsa, tam da bu nedenle, ataerkillliği, rrkçılı̆̆ ve diğer ayrımcı süreçleri anlamayı gerektirdiğini vurguluyor.

Piketty, Eisenstein'in belirtiği gibi bu konuda hiç de yalnız değil. Üstelik de öncesine kıyasla artık piyasa dışı ekonomiye ilişkin verilerin de mevcut olduğunu hatırlatan Eisenstein, zaman kullanım verileri kullanılarak görünen ve görünmeyen ekonominin, piyasanın dışında bırakılan alanda üreten, ücret karş1lığ olmayan emeğin ölçümlenebildiğinden de söz ediyor. Aslında karşılıksız emeğin iktisadi öneminin keşfi yeni değil. Bakım emeğinin iktisadi refahı artırdığı, kişinin ve bulunduğu hanede yaşayan bireylerin yaşam kalitesini yükselttiği düşüncesine bugünkü iktisadın kurucularının yazdıklarında da rastlanıyor. Marshall, Pigou ve Edgeworth'un bile hane içi üretimin öneminin farkında olduklarını ilgili dönemde erkekler için aile ücreti politikasını önermelerinden anlıyoruz. Fakat buna rağmen eşitsizlik meselesine ilişskin analizlerde ne yazik ki yer bulamıor. Eisenstein değerlendirmesinde Piketty'in servet eşitsizliğini anlatırken servet sahibi olmayanları inceleme dışı bıraktığını, sermaye birikiminden söz ederken sermayenin üretim sürecinden bahsetmediğini ve dahasını ekleyerek, kitabın kendisi için bir düş kırıklığı olduğunu da gizlemiyor.

$\mathrm{Bu}$ değerlendirmelere katılmamak elde değil. 21. yüzyılda sermaye ve birikim süreci, sermaye olmayanı tartışmadan anlatılmaya çalışılıyor. Metayı, meta olmayanı anlamadan çözümlemeye çalıştığımız gibi. Acaba Piketty, alıntılar yaptığı romanlara örneğin Amerikalı yazar, Ann Lane Petry'nin 'Sokak' adlı romanını da eklemiş olsaydı, eşitsizliğin azaldığı/arttığı dönemleri yine bu şekliyle mi anlatırdı? Bahsettiği iki savaş arası yılların kimler için daha eşit, daha demokratik ve daha refah içinde geçen bir dönem olduğu bilgisini atlar mıdı yine? Bugün yazında, bazılarının tüm dönemlerde daha eşit, bazılarının ise daha yoksul ve güvencesiz olduğunu ortaya koyan pekçok araştırma mevcut. Ancak o çalışmalar hiç bu kadar yoğun ilgi görmemişlerdi, 21. yüzyıl eşitsizlik analizinde de göz ardı edildiler. Kitap bir düş kırıklığı yaratt1 önemli bir kesimde. Yarattı yaratmasına da kendilerine yeni ödevler çıkarmayı da ihmal etmedi sözünü ettiğim araştırmacılar (Humphreys, 2014).

İşte bu bağlamda, yazının izleyen bölümünde Piketty'nin sonuç olarak vardığı noktadan devam etmek: eşitsizliği ölçmenin hiçbir zaman yansız (nötr) 
olamayacağ1 (s.249) düşüncesini yoksulluk ölçümüne taşıyarak, yoksulluğu farklı bir açıdan tartışmaya açmak istiyorum. Piketty, yazında artık standart hale gelmiş olan Gini katsayısının eşitsizliği adeta doğallaştıracak derecede yaygın biçimde kullanıldığını belirtiyor (s. 26). Benzer biçimde çok yaygın kullanılan yoksulluk ölçümlerinin de, hiçbir biçimiyle yansız olduğu düşünülemez. Ardındaki varsayımların yalnızca bilimsel endişe kaynağı olamayacağını aynı zamanda toplumsal yaşamı somut biçimde etkileyen araçların yapı taşlarını oluşturduğunun da altı çizilmeli.

Örneğin yaygın biçimde kullanılan geleneksel ölçüm yöntemlerinde kullanılan yoksulluk sinırları belirlenirken asgari refah düzeyini sağlayacak, gıda, barınma, eğitim, sağlık gibi temel gereksinimlerin karşılanmasında hane içinde karşılanan bakım ihtiyaçları göz ardı edilir. Öte yandan bireylerin yaşamlarını sürdürebilmelerinde, çocuk bakımı ve hane bakımı hizmet ihtiyacının karşılanması en az diğerleri kadar yaşamsal ve belirleyicidir. Türkiye'de de diğer ülkelere benzer biçimde resmi yoksulluk ölçümü, örtük bir biçimde, tüm yetişkin fertlerin, hane içindeki ihtiyaçları karşılamaları için gerekli kaynağa sahip olduklarını varsayar. Bakım hizmetlerini kendileri yerine getiremeyen ve aynı zamanda piyasadan ikame mal ve hizmetleri satın alarak kapatabilecek güce sahip olmayan fertlerin başetmek zorunda oldukları güçlükler resmi ölçümlere yansımaz.

Bu düşünceyle daha önce yaptığımız bir çalışmada ${ }^{1}$ Eisenstein'ın sözünü ettiği zaman kullanım veri setini hanehalkı bütçe verisini eşleştirerek, Türkiye'de yoksulluğu, salt gelir/tüketim açıkları ile sınırlı kapsamının dışına çıkarmaya çalıştık. Her hane için, gerekli hane içi hizmet ihtiyaçlarının tüketim ihtiyaçlarıyla birlikte hesapladık. Bakım ihtiyaçlarını karşılayabilecek yeterli zamanı olmayan fert ve hanelerin arasında, tüketim düzeyleri, bu açığı piyasadan satın aldıkları mal ve hizmetlerle karşılayabilecek kadar resmi yoksulluk sınırının üzerinde olmayanları "gizli yoksul" olarak tanımladık. Tüketim boyutuna yalnızca bir boyut daha eklediğimiz bu ölçümle, Türkiye'de yoksulluk sınırı altında yaşayan fert sayısının TÜİ'in resmi rakamların yaklaşık bir buçuk katı kadar olduğunu gözlemledik. Hesaplanan yoksulluk oranının yüzde 11 puan daha üzerinde çıkıyor ülke genelinde oran (Şekil 1). Kentlerde 1 milyon, kırsal alanda ise 800 bin hane yoksulluk sınırının altında yaşayan hane grubuna katılıyor. Gizli yoksul olarak nitelendirdiğimiz bu hanelerde, resmi rakamlara yansımayan, 7.6 milyon fert yaşıyor.

${ }^{1} \mathrm{Bu}$ kısım daha önce Ekonomik Yaklaşım (Sayı 25 (91), s. 1-33) dergisinde yayınlanmış olan "Time Deficits and Poverty" başlıklı çalışmanın bulgularından yararlanılarak hazırlanmıștır. Makalenin araștırma raporuna ulaşmak için baknız: http://www.levyinstitute.org/publications/?docid=2071. 
Türkiye'de zaman açıklarına en yüksek oranda maruz kalanlar yoksul hanelerde yaşayan kadınlar (Tablo 1). İşgücü piyasasında çalışanlara yoğunlaşıldığında ise, kadınların işgücüne katılım oranı ve istihdam oranı erkeklere kıyasla çok düşük olmasına rağmen, oranın en yüksek olduğu grubun yine çalışan kadınlar olduğu görülüyor. $\mathrm{Bu}$ sonuç hem kırsal kesim hem de kentte yaşayan nüfus için geçerli. Türkiye genelinde çalışan ve yoksul hanelerde yaşayan kadınların yüzde 68'inin, bu hanelerde yaşayan erkeklerin de yüzde 42'sinin zaman yoksulu olduğunu belirledik. Haftalık çalışma sürelerine göre incelediğimizde ise kadın erkek farkı daha da artıyor. Tam zamanlı çalışan kadınların yüzde 70'i, erkeklerin ise yüzde 37'si zaman bakımından yoksul. Türkiye'de en yaygın çalışma saati olan haftalık 36-50 saat çalışan kadınların yoksulluk oranı erkeklere kıyasla altı kat daha fazla. Zaman açıkları yoksulluk oranlarının yanısıra yoksulluğun derinliğini de etkiliyor. Fertlerin yaşadığı zaman açığının en önemli nedeni işgücü piyasasında gelir getirici işlerde harcadıkları uzun çalışma saatleri. Zaman yoksulu olan on milyon fert içinde yaklaşık bir milyon kişi sadece hane içinde bakım işlerine harcadıkları uzun saatler nedeniyle zaman yoksulu ve bu kitlenin neredeyse tamamı kadınlardan oluşmakta. Yalnızca tam zamanlı çalışanlar değil yarı-zamanlı çalışanlar arasında da zaman yoksulluğunun oldukça yaygın olduğu görülüyor. Örneğin; 35 saat ve altında çalışanlar arasında erkeklerin yüzde 4'ü, kadınların ise yüzde 37'si zaman yoksulu (Şekil 2). Çalışan kadınların haftada ortalama 31 saat, erkeklerin ise sadece 7 saat hane içi bakım işlerine zaman ayırdığı göz önüne alındığında, bu hiç de şaşırtıcı bir sonuç değil. Ayrıca, zaman açıklarının derinliği de cinsiyet farklılıklarına yönelik önemli bulgular sağllyor. Örneğin, orta gelir düzeyinde çalışan kadın zaman açığını piyasadan ikame ederek kapatmak istiyorsa gelirinin yarısını harcamak zorunda. Bu sonuç kadın erkek arasındaki eşitsizliğin sadece zaman boyutuna değil piyasadaki eşitsiz ücret/gelir farkına da işaret ediyor. Son olarak, burada sadece bazılarını aktardığım bu bulgular, hangi ölçüm kullanılırsa kullanılsın tıpk1 eşitsizlik göstergelerinde olduğu gibi yoksulluk ölçümlerinde de yansız bir yöntem olamayacağı konusunda deliller ortaya koyuyor. 
Ankara Üniversitesi SBF Dergisi • 69(3)

\section{Kaynakça}

Ayınonat, E. Piketty Deliliği http://neaydinonat.com/?tag=piketty

Boratav, Korkut Thomas Piketty'nin KAPITAL'i http://www.sendika.org/2014/08/thomas-pikettyninkapitalikorkut-boratav/

Eisenstein, Zillah. An Alert: Capital is Intersectional; Radicalizing Piketty's Inequality: http://thefeministwire.com/2014/05/alert-capital-intersectional-radicalizing-pikettysinequality/

Galbraith, James K. (2014). Kapital for the Twenty-First Century?. Dissent, 61(2), 77-82.

Humphries, Jane. (2014). Capital in the Twenty-First Century. Feminist Economics, 1-10.

Köse, Ahmet H. Thomas Piketty: 21. yüzyılda sermaye mi dediniz? http://haber.sol.org.tr/ekonomi/thomas-piketty-21-yuzyilda-sermaye-mi-dediniz-haberi91921

Patnaik, Prabhat. Capitalism, Inequality and Globalization: 'Thomas Piketty's Capital in the TwentyFirst Century

Piketty, T. (2014). Capital in the Twenty-first Century. Harvard University Press.

Taylor, Lance. Thomas Piketty's Capital in the Twenty-First Century: Introduction to a Structuralist Symposium.

Tonak, Ahmet E. Yirmibirinci Yüzyılda Kapital ${ }^{*}$ (mi?) - E. Ahmet Tonak http://www.sendika.org/2014/05/yirmibirinci-yuzyilda-kapital-mi-e-ahmet-tonak/

Şekil 1. Resmi* ve LIMTCP yoksulluk oranları

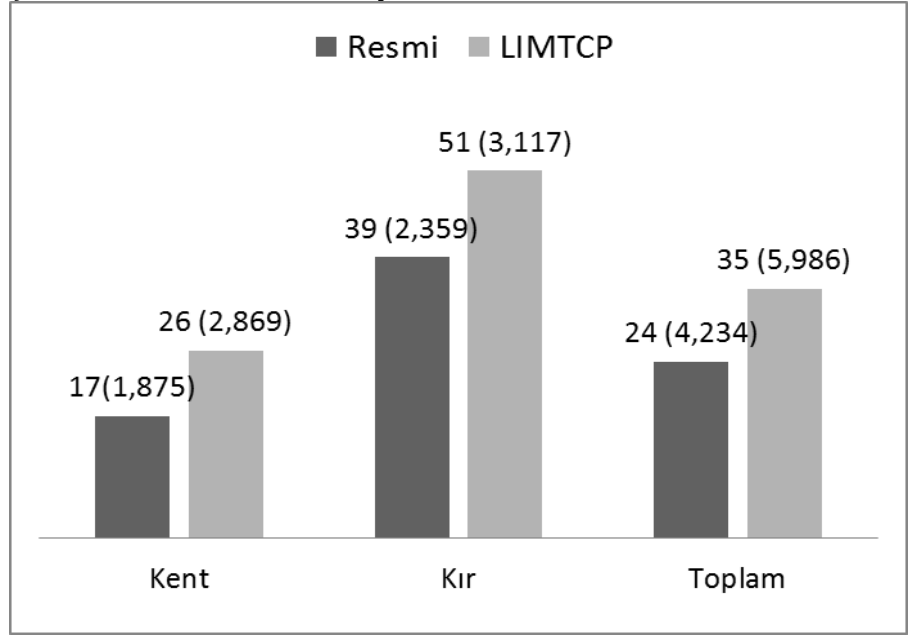

*Bu oranlar, açlık sınırı hesaplanmasında kullanılan günlük ortalama 2100 kcal yerine bir yetişkin için gerekli olan 2450 kcal'ye göre uyarlanarak hesaplanmıştır. 
Tablo 1 Zaman yoksulluğu, cinsiyet ve yoksulluk durumuna göre

\begin{tabular}{|c|c|c|c|c|}
\hline & & & Toplam & Çalışan \\
\hline \multirow{4}{*}{ Türkiye } & \multirow{2}{*}{$\begin{array}{l}\text { Yoksul } \\
\text { olmayan }\end{array}$} & Erkek & 21 & 29 \\
\hline & & Kadın & 12 & 48 \\
\hline & \multirow{2}{*}{ Yoksul } & Erkek & 34 & 42 \\
\hline & & Kadın & 32 & 68 \\
\hline \multirow{4}{*}{ Kent } & \multirow{2}{*}{$\begin{array}{l}\text { Yoksul } \\
\text { olmayan }\end{array}$} & Erkek & 21 & 29 \\
\hline & & Kadın & 11 & 48 \\
\hline & \multirow{2}{*}{ Yoksul } & Erkek & 33 & 42 \\
\hline & & Kadın & 21 & 68 \\
\hline \multirow{4}{*}{ Kir } & \multirow{2}{*}{$\begin{array}{l}\text { Yoksul } \\
\text { olmayan }\end{array}$} & Erkek & 19 & 24 \\
\hline & & Kadın & 18 & 42 \\
\hline & \multirow{2}{*}{ Yoksul } & Erkek & 29 & 34 \\
\hline & & Kadın & 44 & 67 \\
\hline
\end{tabular}

Şekil 2. Zaman yoksulluk oran1- işgücü piyasasında çalışanlar

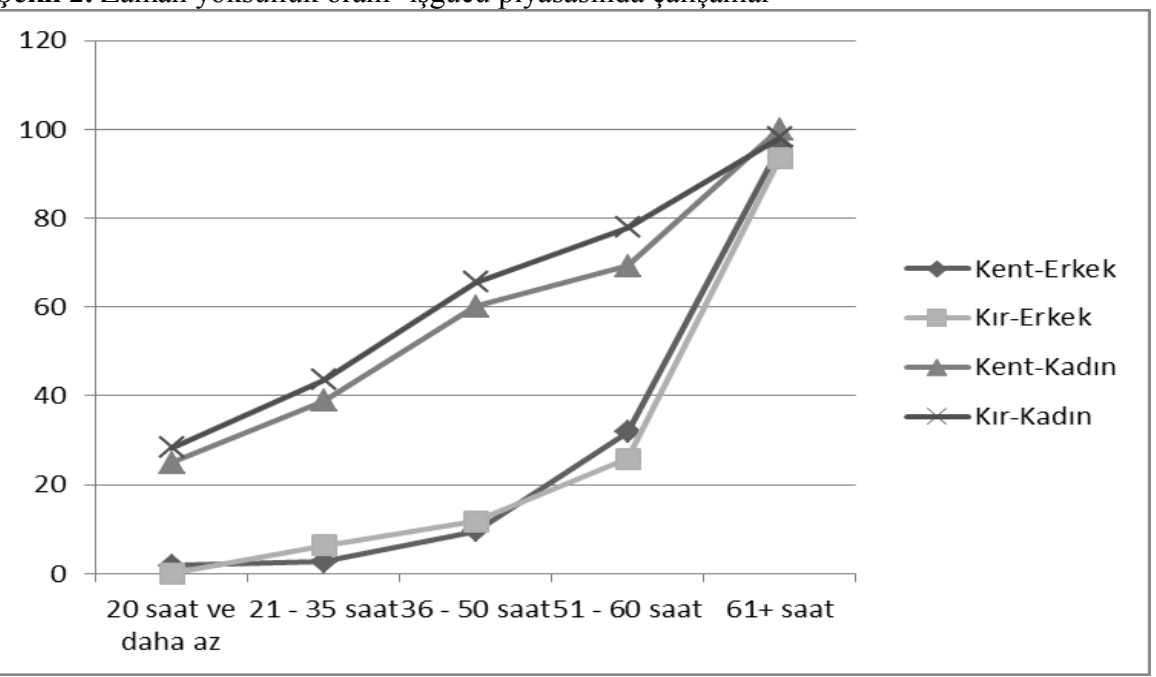

